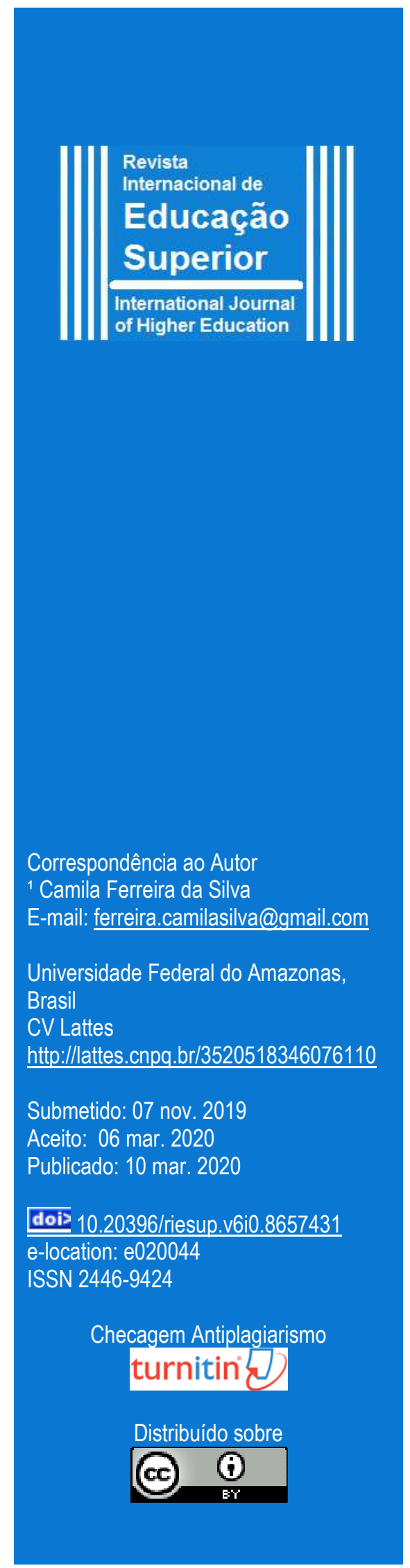

\title{
A Agenda de Pesquisa em Sociologia da Educação na Pós-graduação Brasileira1
}

Camila Ferreira da Silva 1 http://orcid.org/0000-0002-2348-9350

Rodrigo de Macedo Lopes² (ib) http://orcid.org/0000-0002-7047-4530

Amurabi Oliveira3 $^{\text {ht }}$ htp://orcid.org/0000-0002-7856-1196

${ }^{1}$ Universidade Federal do Amazonas, 2 Universidade Federal do Rio Grande do Sul, ${ }^{3}$ Universidade Federal de Santa Catarina.

\section{RESUMO}

Os exercícios de autorreflexão têm marcado a história da Sociologia da Educação (SE) no Brasil: ao passo que a disciplina tem se desenvolvido, pesquisadores que a compõem têm se dedicado a pensar as suas bases, sua trajetória, disputas e contradições. O fato de, nesse país em específico, a SE estar situada na interseção de duas áreas - a Sociologia e a Educação confere-lhe uma heterogeneidade particular. $\mathrm{O}$ presente artigo toma esta interseção à análise e se propõe a dar continuidade ao debate acerca das especificidades da SE brasileira, para tal toma como objeto de estudo a sua agenda de investigação. Os programas de pós-graduação (PPGs) de Sociologia e de Educação serviram de base para o mapeamento das linhas de pesquisa diretamente ligadas à $\mathrm{SE}$, os professores/pesquisadores credenciados em tais linhas tiveram seus currículos escrutinados com vistas a mapear os projetos de pesquisa em andamento, estes projetos, por fim, constituíram nossa principal fonte para traçar a agenda de pesquisa da Sociologia da Educação na atualidade.

\section{PALAVRAS-CHAVE}

Sociologia da educação. Sociologia brasileira. Campo acadêmico. Agenda de pesquisa.

\footnotetext{
${ }^{1}$ Este artigo foi originado a partir dos dados compilados e organizados pela investigação de pós-doutorado "Sociologia da educação no Brasil: continuidades, rupturas e disputas", desenvolvida entre 2018 e 2019.

\begin{tabular}{l|c|c|c|c|c} 
(C) Rev. Inter. Educ. Sup. & Campinas, SP & v.6 & $1-21$ & $\mathrm{e} 020044$ & 2020 \\
\hline
\end{tabular}
}




\title{
The Research Agenda in Sociology of Education in Brazilian Postgraduate Programs
}

\section{ABSTRACT}

The self-reflection exercises have marked the history of the Sociology of Education (SE) in Brazil: while the discipline has developed, its researchers have dedicated themselves to thinking about its foundations, trajectory, disputes and contradictions. The fact that in this particular country SE lies at the intersection of two areas sociology and education - gives it a particular heterogeneity. This article takes this intersection to the analysis and proposes to continue the debate about the specificities of the Brazilian SE, for such it takes as its study object its research agenda. Sociology and Education postgraduate programs (PPGs) served as the basis for mapping of research lines directly linked to SE, accredited teachers / researchers on such lines had their curricula scrutinized to map research projects. In the current research, these projects, finally, were our main source to outline the research agenda of the Sociology of Education today.

\section{KEYWORDS}

Sociology of education. Brazilian sociology. Academic field. Reserch agenda.

\section{La Agenda de Investigación de la Sociología de la Educación en los Programas de Posgrado Brasileños}

\begin{abstract}
RESUMEN
Los ejercicios de autorreflexión han marcado la historia de la Sociología de la Educación (SE) en Brasil: mientras la disciplina se ha desarrollado, sus investigadores se han dedicado a pensar en sus fundamentos, trayectoria, disputas y contradicciones. El hecho de que en este país en particular SE se encuentre en la intersección de dos áreas - sociología y educación - le da una heterogeneidad particular. Este artículo lleva esta intersección al análisis y propone continuar el debate sobre las especificidades de la SE brasileña, ya que toma como objeto de estudio su agenda de investigación. Los programas de posgrado en Sociología y Educación (PPG) sirvieron como base para el mapeo de líneas de investigación directamente vinculadas a SE, los profesores/investigadores acreditados en esas líneas tuvieron sus currículos analizados para mapear proyectos de investigación. En la investigación actual, estos proyectos, finalmente, fueron nuestra principal fuente para delinear la agenda de investigación de la Sociología de la Educación de hoy.
\end{abstract}

PALABRAS CLAVE

Sociología de la educatión. Sociología brasileña. Campo académico. Agenda de investigación. 


\section{Introdução}

O presente artigo toma a Sociologia da Educação (SE) brasileira à análise como uma "parte", posicionada no "todo" da Sociologia desse país, dotada de especificidades históricas e lutas próprias em torno do estabelecimento de suas bases. Tais lutas, como a literatura especializada demonstra há pelo menos três décadas (GOUVEIA, 1989; WEBER, 1992; OLIVEN, 1998; NEVES, 2002; COSTA; SILVA, 2003; COSTA; NOGUEIRA, 2009; MARTINS; WEBER, 2010; OLIVEIRA; SILVA, 2014; CÊA; SILVA, 2015; ALMEIDA; HEY, 2018; BARBOSA; GANDIN, 2020), são reveladoras das relações entre as áreas da Sociologia e da Educação como espaços nos quais a SE tem se desenvolvido e se reproduzido por meio de sua consolidação e da formação de novos quadros.

Em que pesem as diferentes conclusões às quais tais balanços chegaram, é perceptível que eles convergem no sentido de reafirmar a estabilidade e contínua expansão desse campo de pesquisa. Reconhece-se ainda sua interdisciplinaridade, que se fundamenta na interface entre a Sociologia e a Educação, o que tem se intensificado em anos recentes (BALL, 2004; BARBOSA; GANDIN, 2020). Esta característica interdisciplinar, todavia, não perde em seu horizonte as características disciplinares na Sociologia, que possibilitam o desenvolvimento de pesquisas centradas, sobretudo, na relação entre desigualdades sociais e escolarização (FORQUIN, 1995), principalmente nas sociedades modernas, que constituem o escopo de análise por excelência da sociologia (GIDDENS, 1997). Sendo assim, os balanços encontram no montante da produção analisada a reafirmação da Sociologia como disciplina que observa a educação por um ângulo desnaturalizante socialmente, e que possibilita no bojo de seus resultados investigativos o lastreamento de políticas públicas (SEBASTIÃO; CAPUCHA; MARTINS; CAPUCHA, 2020).

A partir da objetivação da interseção das áreas em questão, os balanços acerca da SE no Brasil têm se multiplicado nos últimos anos, o que revela uma retomada dos exercícios de autorreflexão neste terreno. É importante apontar desde já que esta elaboração é realizada tanto por pesquisadores vinculados institucionalmente às Faculdades de Educação, quanto por aqueles situados em Departamentos de Ciências Sociais/Sociologia. Esta clivagem institucional, talvez uma das marcas mais incisivas deste campo, constitui o nódulo central na análise aqui empreendida, uma vez que apesar de haver o reconhecimento, por parte dos balanços acima citados, da elaboração de distintas agendas nestes espaços, tem sido dada pouca atenção a uma análise mais empírica acerca das diferenças constitutivas existentes.

A partir de uma perspectiva bourdieusiana, o presente texto enfrenta a tarefa de objetivar as temáticas e objetos sobre os quais os pesquisadores ligados à Sociologia da Educação têm se debruçado atualmente. Com o objetivo principal de analisar a agenda de investigação desenvolvida pelos pesquisadores que atuam no campo da SE no Brasil, os programas de pós-graduação de Sociologia e de Educação figuram aqui como primeira fonte de informações e dados, seguidos dos currículos desses pesquisadores, dos quais retiramos as informações relativas ao nosso objeto empírico: os seus projetos de pesquisa em andamento. 
Antes de iniciarmos discussões sobre nosso objeto de estudo, é importante provocar o leitor a pensar conosco sobre uma questão que pode ser colocada como fio condutor deste artigo: por que objetivar o que chamamos de agenda de pesquisa? Tornou-se cada vez mais comum publicar trabalhos de referência, sejam artigos ou livros, preocupados em refletir sobre os caminhos que cada área de conhecimento seguiu ao longo do tempo. No entanto, é bastante comum nesse tipo de exercício ser quase ingênuo ao lidar com dados e resultados, e é precisamente aqui que este artigo tenta quebrar a passividade com os resultados desse tipo de estudo. Uma agenda de pesquisa nunca é apresentada apenas superficialmente: ela é o resultado de disputas históricas dentro de uma disciplina e no âmbito de suas relações com outras disciplinas no campo científico. É também uma expressão do exercício da força simbólica, do capital em ação e das posições dos agentes e instituições que compõem esse espaço acadêmico e, justamente por essas características, quando enfrentamos dados sobre temas, objetos, teorias, epistemologias e métodos que surgem da análise de uma disciplina, histórica e geograficamente localizada, também enfrentamos uma das manifestações das relações de poder estabelecidas no campo da ciência.

$\mathrm{O}$ artigo encontra-se organizado da seguinte forma: em um primeiro momento ocupamo-nos com o debate em torno da agenda de investigação de uma determinada disciplina e o que este debate pode revelar, são aqui apontados os conflitos que geralmente são invisibilizados pelo sistema de hierarquização de temas e objetos legítimos; logo depois, promove-se um desdobramento desta discussão e a Sociologia da Educação brasileira é brevemente apresentada em uma perspectiva que flerta com a reconstrução histórica, mas que no fundo se preocupa em apreender o movimento de oscilação na agenda de pesquisa ao longo do tempo; uma sucinta nota metodológica faz a ponte entre essas duas primeiras partes e a apresentação, discussão e análise dos achados da pesquisa.

\section{Agendas de Investigação: 0 que Revelam?}

Os processos históricos de autonomização de determinada área do conhecimento no campo científico são constituídos de complexos movimentos, nem sempre coordenados ou com a mesma finalidade a curto e a longo prazos, que acabam por construir as condições de possibilidade de elaboração e consolidação de um aparato institucional, de recursos humanos e de produtos acadêmicos próprios e compatíveis com o "jogo científico" (BOURDIEU, 2008).

De modo geral, esse processo de ganho de autonomia ocorre ao passo que vão de estabelecendo as regras, as normas tácitas, as disputas e as lutas em torno da hierarquia de capitais (econômico, social, cultural ou ainda científico ou político), de objetos, de epistemologias, de métodos e de posições. A heterogeneidade que marca determinada área do conhecimento no interior do campo científico é expressão de como acabam por serem dispostos desigualmente os elementos em disputa. 
Esta compreensão nos possibilita mirar aquilo que fazem os pesquisadores, ou seja, seu ofício, de modo correlacional: suas trajetórias formativas, as posições que ocupam no campo e, consequentemente, os temas a que se dedicam [e como o fazem] constituem elementos que nos comunicam, de forma concomitante, a história do agente e a história do "espaço acadêmico específico" (SILVA, 2017) que ele compõe. Na confluência dessas duas instâncias, individual e coletiva, figura um elemento crucial para o exercício de autorreflexão do campo científico - exercício este que que já pode ser considerado clássico no âmbito da filosofia, da história e da sociologia da ciência, do conhecimento ou das ideias, bem como mais recentemente nos estudos e pesquisas denominados "estado da arte", "estado do conhecimento" ou "estado da questão". Estamos a falar das agendas de pesquisa.

Ao passo que são construídas as bases de uma disciplina científica e que seus agentes vão racionalizando, desenhando e consolidando consensos em torno do ofício do pesquisador, vai ganhando corpo um horizonte de problemas e temas considerados relevantes em cada panorama de época (FOUCAULT, 2008). É o movimento de legitimação e de disposição em relação hierárquica e desigual de importância que acaba por determinar uma agenda de investigação, que vai ser assumida e levada a cabo pelos agentes.

O "olho disciplinar" (BOURDIEU, 2008), ou seja, o nomos particular, ou ainda, o modo de ver, dividir e construir a realidade de cada disciplina nos concede, afinal, uma pista para compreender como esta autonomia relativa opera na prática científica, por um lado, e como as tautologias são construídas e hierarquizadas. No que tange ao estabelecimento de uma agenda de pesquisa, estamos a falar então das disputas no interior de uma disciplina em torno da validação de teorias, paradigmas, metodologias, temas, objetos e também nomes próprios. Tais disputas correlacionadas sintetizam o modo como as hierarquias se colocam no cotidiano da investigação universitária. Sobre isso, Bourdieu (2013, p. 35) afirma:

\begin{abstract}
A hierarquia dos objetos legítimos, legitimáveis ou indignos é uma das mediações através das quais se impõe a censura específica de um campo determinado que, no caso de um campo cuja independência está mal afirmada com relação às demandas da classe dominante, pode ser ela própria mascarada de uma censura puramente política. A definição dominante das coisas boas de se dizer e dos temas dignos de interesse é um dos mecanismos ideológicos que fazem com que coisas também muito boas de se dizer não sejam ditas e com que temas não menos dignos de interesse não interessem a ninguém, ou só possam ser tratados de modo envergonhado ou vicioso.
\end{abstract}

Tomar, pois, a agenda de investigação à análise constitui um exercício que, além de mapear temas, problemas e abordagens, nos permite compreender melhor as disputas em torno da validação de frentes de pesquisa nos diferentes momentos históricos. Tal mirada é reveladora, ainda, de agendas e forças de legitimação heterogêneas, marcadas por diferenças regionais, influências internacionais, disputas teóricas e até diferenças políticas. A posição e o peso dos capitais caros à ciência e à academia tornam-se, nesse contexto, determinantes para o exercício do poder de vanguarda e de tornar-se referência no âmbito da agenda, poder que exerce influência sobre outros agentes do campo - aspirantes ou já posicionados em seu 
interior - no sentido de darem continuidade a esta agenda, por meio do reconhecimento de sua relevância, por uma defesa pública em prol dela, ou até mesmo pela atração de jovens pesquisadores que enxergam nos "vanguardistas" uma ótima chance de inserção na agenda de pesquisa vigente, de modo mais específico, e no campo científico, de modo mais geral.

Com a relação entre globalização e ensino superior cada vez mais acentuada e com suas consequências a níveis local, nacional e internacional paulatinamente mais drásticas (MARTINS, 2015; BIANCHETTI, 2015), atualmente falar de agenda de investigação de uma disciplina em um contex to geográfico específico é, em certa medida, tratar também de temas caros à disciplina em questão em um nível transnacional. Naturalmente, isso não significa que haja uma agenda única para os pesquisadores de um mesmo campo a nível global. Significa, por outro lado, que os temas e objetos localmente situados dialogam de forma bastante profícua com temas, objetos e preocupações compartilhadas em um nível mais amplo por diferentes países.

A objetivação da agenda de pesquisa é reveladora, portanto, do jogo científico em sua expressão de produto simbólico: é materializado nas temáticas de pesquisa o sistema de valores ratificado no interior do campo científico. Se o corpo do pesquisador, em função de sua formação e socialização, é extensão da doxa do campo científico (BOURDIEU, 2011; SILVA; ALVES, 2018), a agenda de pesquisa é um elemento crucial para a dialética que se faz presente nos movimentos mútuos de inserção no campo, incorporação da lógica desse espaço social e aceitação em jogar o jogo.

Olhar para a SE no Brasil, por meio da agenda de pesquisa que vem se desenhando no cenário recente, nos permite dar continuidade aos movimentos de autorreflexão que têm marcado a literatura nacional, bem como representa um avanço no debate em torno daquilo que tem sido eleito como horizonte de preocupação dos pesquisadores que compõem o espaço da SE nesse país. No plano dos desdobramentos deste olhar, é possível também atentar para as correlações entre ensino, pesquisa e extensão no contexto nacional, em função da configuração das universidades brasileiras. Desse modo, a agenda de pesquisa da Sociologia da Educação torna-se também uma expressão relevante para pensarmos a formação de professores (pensando as licenciaturas em Ciências Sociais/Sociologia e em Pedagogia) e de bacharéis (neste caso mais detidamente no âmbito das Ciências Sociais/Sociologia). Isso se evidencia na relação entre esta agenda de pesquisa e os currículos e projetos políticopedagógicos dos cursos em questão, afinal, os agentes responsáveis pela legitimação da agenda são os mesmos que atuam na definição e atualizações desses currículos, estabelecendo aí uma continuidade nos seus papeis.

Ademais, tanto a agenda de pesquisa quanto os currículos dos cursos supracitados no ensino superior, sendo frutos de disputas em torno de uma perspectiva de sociedade e estando em relação constante com diferentes espaços sociais nas suas definições, acabam por revelar pressupostos políticos, econômicos e visões de homem e mulher e de relações sociais. Em última instância, a agenda de pesquisa é ainda um vértice para compreendermos os sentidos e direcionamentos dos compromissos éticos, sociais e políticos das instituições [universidades, 
órgãos de pesquisa, veículos de circulação de publicações, agências de fomento etc.] e dos agentes que a constroem, a legitimam e a reproduzem.

\section{A Sociologia da Educação no Brasil: Uma Mirada para a Relação entre sua História e suas Agendas}

O estabelecimento da Sociologia no Brasil passa necessariamente pela educação como objeto de pesquisa. Neste tópico trataremos de apresentar as diferentes fases que a SE atravessou ao longo de sua história com foco na agenda de pesquisa que emerge de cada panorama de época - não se trata de um arrolamento de fatos históricos sobre a área ${ }^{2}$, trata-se de um movimento de apreender da literatura especializada as principais inclinações que marcaram a SE no país.

As primeiras décadas do século XX são assinaladas pela presença da Sociologia nas escolas normais (MICELI, 1989), pela tradução de obras de sociólogos internacionalmente reconhecidos e ainda pela produção de sínteses sociológicas originais - ainda que, de fato, pautadas em pensadores estrangeiros. Neste contexto ganham destaque a produção de manuais de sociologia voltados para o ensino nas escolas normais, principais instituições formadoras de professores àquele tempo, nos quais autores como Durkheim, Le Play e Dewey ganham destaque (MEUCCI, 2011). É importante apontar ainda que majoritariamente os autores responsáveis por realizar tais sínteses eram autodidatas no campo da sociologia, salvas poucas exceções como no caso de Gilberto Freyre (1900-1987), que havia realizado cursos de sociologia durante seu mestrado em História Social na Universidade de Colúmbia na década de 1920, e que veio a assumir a cátedra de Sociologia em 1928 na escola normal de Pernambuco, lançando um manual de sociologia em 1945.

É importante compreender esse movimento no contexto da tentativa de modernizar a escola e, por consequência, a sociedade brasileira. Como bem indica Meucci (2011), a introdução da Sociologia representava a tentativa de se distanciar de certo conhecimento demasiadamente "literário" existente no sistema escolar, trazendo para ele "realismo sociológico". A Sociologia, tanto na formação docente quanto nos cursos complementares da educação secundária, visava contribuir para a formação científica no sistema escolar e para desvelar questões socialmente relevantes, o que seria algo fundamental para a consolidação da transição da velha para a nova República.

Importante ainda indicar que muitos dos primeiros docentes de Sociologia que passaram a atuar nas escolas normais estavam vinculados às reformas educacionais que vinham ocorrendo nos estados, e também em nível nacional, principalmente entre as décadas de 1920 e 1930. Muitos deles se vincularam à Associação Brasileira de Educação (ABE), criada em 1924, como nos casos de Fernando de Azevedo (1894-1974) e Alceu Amoroso Lima (1893-1983), que representaram algumas das mais destacadas lideranças nesta

${ }^{2} \mathrm{O}$ que o leitor pode consultar em textos como Silva (2002) ou Beisiegel (2013).

\begin{tabular}{l|l|l|l|l|l} 
(C) Rev. Inter. Educ. Sup. & Campinas, SP & v.6 & $1-21$ & e020044 & 2020
\end{tabular}


instituição, capitaneando o embate entre liberais e católicos na mesma, cujo ponto máximo de tensão veio a eclodir com a publicação do Manifesto dos Pioneiros da Educação Nova, que teve Azevedo como um de seus principais redatores (CURY, 1988).

Todos esses movimentos não coordenados são expressões dos primeiros passos da SE no país, dos quais evidencia-se um primeiro esforço no sentido de refletir sobre a educação nacional pelas lentes da Sociologia. Neste primeiro momento fica clara a preocupação com a educação como um direito frente aos índices de baixa escolarização da população brasileira. Há que se destacar o paralelo entre estes primeiros passos, como estamos a denominar, e as transformações pelas quais o Brasil estava a passar com a chamada "Era Vargas" (1930-1945) e sua tônica no desenvolvimentismo.

É nesse momento que o próprio campo educacional passa a se desenvolver no Brasil, com a criação das primeiras experiências universitárias, da ABE (como anteriormente mencionado), com o advento do Ministério dos Negócios da Educação e Saúde Pública em 1930, e com a elaboração dos primeiros esforços de criar políticas educativas de caráter nacional. No Brasil, à medida que a educação passa a ser tomada como meio ou instrumento para a efetivação de um ideal de desenvolvimento econômico e social, por parte do Estado, ela passa também a despertar maior interesse no circuito da investigação - naturalmente essas duas faces do fenômeno estão correlacionadas, posto que é a partir daqui que começa a haver um incentivo e financiamento mais sistemático para o desenvolvimento de pesquisas sobre a educação no sentido de orientar as próprias tomadas de decisões no nível da política nacional, o que se consolida nas décadas posteriores. Concomitante a esse momento são criados os primeiros cursos de Ciências Sociais a partir da década de $1930^{3}$, ao mesmo tempo em que são publicadas algumas das principais obras no campo das ciências sociais, como "CasaGrande \& Senzala" em 1933 de Freyre, e "Raízes do Brasil” em 1936 de Sérgio Buarque de Holanda (1902-1982).

A década de 1950, por conseguinte, muito em função dos processos de modernização do país proporcionados pelo governo de Juscelino Kubitschek, passa a registrar pesquisas sociológicas que tomam pela primeira vez a educação como objeto empírico. As ciências sociais, de maneira mais ampla, neste momento histórico, tomam para si o papel de pensar sobre os processos de urbanização e industrialização pelos quais o Brasil passava, pelo que a relação entre educação/escolarização e desenvolvimento/prosperidade acaba por amparar boa parte das explicações ensaiadas nessa altura (GOUVEIA, 1989). Instituições de pesquisa foram cruciais para a consolidação da Sociologia da Educação e dessa agenda de pesquisa desenvolvida na primeira metade do século XX, com destaques para o Instituto Nacional de Estudos e Pesquisas Educacionais Anísio Teixeira (INEP) e o Centro Brasileiro de Pesquisas Educacionais $(\mathrm{CBPE})^{4}$.

\footnotetext{
${ }^{3}$ Os primeiros cursos de ciências sociais criados no Brasil são os da Escola Livre de Sociologia e Política de São Paulo (1933), Universidade de São Paulo (1934), Universidade do Distrito Federal (1935), Faculdade de Filosofia, Ciências e Letras do Paraná (1938) e da Faculdade de Filosofia da Bahia (1941).

${ }^{4}$ O Caso do CBPE é emblemático na medida em que sua proposta, elaborada por Anísio Teixeira (1900-1971), visava, justamente, a elaboração de pesquisas desenvolvidas desde as ciências sociais aplicadas ao campo da educação. Durante seu funcionamento entre as décadas de 1950 e 1970 o centro contou com cientistas sociais \begin{tabular}{l|l|l|l|l|r} 
(C) Rev. Inter. Educ. Sup. & Campinas, SP & v.6 & $1-21$ & e020044 & 2020 \\
\hline
\end{tabular}
} 
Notadamente é a partir das décadas de 1940 e 1950 que passam a eclodir os resultados de um conjunto de pesquisas desenvolvidas pela primeira geração de sociólogos profissionais no Brasil. Já na década de 1940 a Escola Livre de Sociologia e Política de São Paulo já havia inaugurado sua divisão de estudos pós-graduados, o que contribuiu para esse processo de forma incisiva.

Ainda em 1954 ocorreu em São Paulo o I Congresso Brasileiro de Sociologia, no qual foram apresentadas, dentre as doze que constam nos anais do evento, as seguintes comunicações: "O papel do estudo sociológico da escola na sociologia educacional", de Antônio Cândido (1918-2017); "O ensino de sociologia na escola secundária brasileira”, de Florestan Fernandes (1920-1995); "Duas experiências no ensino da sociologia”, de Oracy Nogueira (197-1996). Tais comunicações apontam para a centralidade do debate educacional na comunidade de sociólogos brasileiros naquele momento.

Concomitante a esse movimento, a Faculdade Nacional de Filosofia, vinculada à Universidade do Brasil, passa a elaborar um modelo de formação de professores que se populariza no país, a partir do qual os cursos de bacharelado eram sucedidos por uma formação pedagógica que garantiria a habilitação para o ensino na educação básica. Este curso geralmente era composto pelas seguintes disciplinas: fundamentos sociológicos da educação, fundamentos biológicos da educação, psicologia educacional aplicada, administração escolar e educação comparada, didática geral, além das didáticas especiais.

Importante ainda indicar que, apesar da Sociologia ter sido excluída da educação secundária com a Reforma Capanema em 1942, na qual foram extintos os cursos suplementares, a Sociologia educacional continuou a ser lecionada nas escolas normais. E, apesar de haver certo trânsito entre as escolas normais e os cursos de ciências sociais, como aponta a análise de Miceli (1989), houve uma forte reorientação das carreiras em ciências sociais para a pesquisa e o ensino superior. Soma-se a este cenário o fato de que a primeira Lei de Diretrizes e Bases da Educação (LDB) de 1961 garantiu o direito aos egressos das escolas normais de lecionar as disciplinas de tais cursos, de modo que podemos inferir que a Sociologia educacional lecionada nestas instituições passou a se distanciar cada vez mais dos debates desenvolvidos nos cursos de Ciências Sociais.

No âmbito da pesquisa acadêmica, as desigualdades sociais e educacionais passam a ganhar cada vez mais espaço nas pesquisas no terreno da SE brasileira. Passaram a ser correlacionadas as seguintes categorias: origem social familiar, acesso aos níveis de escolarização formal, desempenho e evasão. A exemplo do que ocorrera em outros países, os pesquisadores engajados no campo da SE no Brasil dedicaram-se neste período especialmente a evidenciar o caráter antidemocrático do sistema escolar.

renomados em seus quadros, como Gilberto Freyre, Florestan Fernandes, Darcy Ribeiro (1922-1997), Aparecida Joly Gouveia (1919-1998), ainda que não tenha conseguido atingir plenamente seus objetivos (SILVA, 2002).

\begin{tabular}{l|c|c|c|c|c} 
(C) Rev. Inter. Educ. Sup. & Campinas, SP & v.6 & $1-21$ & e020044 & 2020
\end{tabular} 
A transição da década de 1950 para a década de 1960, no Brasil, acabou por recolocar a questão da educação nacional em debate e em disputas que se transvestiram, ao final, em reformas do sistema escolar, de um lado, e no fortalecimento de movimentos em favor da educação pública, de outro (GOHN, 2019).

As mudanças profundas engendradas pela ditadura militar (1964-1985) levaram muitos pesquisadores das Ciências Sociais a se dedicarem a explicitar as variáveis políticas e suas implicações no terreno educacional (GOUVEIA, 1989). No âmbito institucional a Reforma Universitária de 1968 criou os cursos de pós-graduação no modelo próximo ao que temos hoje, além das Faculdades de Educação, o que possibilitou uma autonomização ainda maior dos campos de investigação das Ciências Sociais e da Educação no Brasil. Para Cunha (1992), encontramos nesta Reforma a gênese da clivagem institucional da SE no Brasil, que seria marcada por um crescente distanciamento do debate desenvolvido entre as Faculdades de Educação e os Departamentos de Ciências Sociais/Sociologia, passando a pesquisa educacional a ser compreendida paulatinamente como uma especialidade de tais Faculdades.

Nogueira (1990), por sua vez, aponta que o final da década de 1960 e o início da década de 1970, no âmbito da SE brasileira, foi um período que privilegiou o debate sobre a reprodução. Sobre isso, Gouveia (1989, p. 74-75) afirma:

\begin{abstract}
A despeito do clima político opressivo criado pelo golpe militar e que na época ainda se fazia sentir, ou talvez por isso mesmo (GOUVEIA, 1985), a década de setenta foi marcada por intensas discussões suscitadas por teorias sobre o caráter conservador da escola, de autoria de sociólogos franceses (Althusser, 1970; Bourdieu, 1974; Bourdieu \& Passeron, 1975; Establet, 1975); que aqui se acoplaram às denúncias de economistas radicais dos Estados Unidos, relativas ao atrelamento dos sistema escolar daquele país aos requisitos do capitalismo.
\end{abstract}

A redemocratização, no entanto, impele o campo científico a ampliar este escopo de discussão. A SE brasileira inicia uma clivagem entre perspectivas macro e microssociológicas e a instituição escolar aparece como principal espaço merecedor de problematizações. $\mathrm{O}$ caráter crítico frente às problemáticas e desigualdades sociais e educacionais, que se devia em alguma medida ao contexto pós-ditatorial, continua a ter fôlego durante a década de 1980 e início dos anos 1990, período no qual a educação passa a ser compreendida como chave fundamental para a consolidação do projeto democrático (WEBER, 1996). A fragmentação teórica, metodológica e, consequentemente, temática passa a marcar a SE a partir de década de 1990: esboçar uma agenda de pesquisa tem sido desde então tarefa mais complexa do que nunca. A expansão do ensino superior, o aumento do número de pesquisadores, a multiplicação de frentes e objetos de investigação, em uma sociedade cada vez mais conectada e com acesso à informação e conhecimento de modo facilitado e rápido, constituem fatores que se colocam como imperativos para a compreensão da atualidade daquilo que têm feito os sociólogos da educação.

Esta breve percorrida na agenda da SE no Brasil, além de evidenciar as tendências temáticas de cada panorama de época, demonstra uma forte correlação entre o momento 
histórico e os problemas, temas e teorias que foram ganhando centralidade nessa trajetória de desenvolvimento da disciplina. Sabe-se - pelo caráter pluriparadigmático da sociologia, como ciência humana que é, e ainda pela heterogeneidade de temáticas que coexistem em seu interior - que quando a literatura aponta os principais temas que marcaram esse campo em cada período de seu desenvolvimento, não significa que não se desenvolveu investigação acerca de outras temáticas no mesmo período. Significa, então, que a agenda de pesquisa legítima, aquela que conseguiu se impor e exercer poder de direcionamento das preocupações de um número mais expressivo de agentes no campo, foi tomada a posteriori como marca daquele momento em particular.

Afinal, o que essa discussão esconde são as disputas no espaço acadêmico específico da Sociologia da Educação, que, apesar da agenda "oficial", abriga muitas outras agendas mais ou menos periféricas sujeitas à dominância da liderança do jogo científico. A disputa historicamente colocada entre os campos da Sociologia e da Educação, no caso da SE brasileira, é um exemplo claro de como o estabelecimento e a legitimação de uma agenda de pesquisa em uma disciplina são processos complexos e necessariamente vinculados às lutas que são travadas no campo e ao poder de indicar o horizonte a seguir: alguns termos que aparecem na literatura sociológica especializada, quando se referem ao trabalho em SE produzido no campo da educação, constituem a terceirização máxima dessa disputa (como "não científica", "parasociológico", "sem qualidade", etc.).

Este processo de lutas e imposições no âmbito da agenda de pesquisa está diretamente relacionado às posições em disputa no interior do campo científico e, não obstante, às correlações entre este campo e as demais esferas sociais, tais como a política e a economia como se evidencia a partir da trajetória da SE que acabamos de sintetizar aqui: a relação com o Estado, as posições em instituições nacionais de pesquisa, o financiamento para se desenvolver investigações sobre determinados temas são, pois, exemplos de elementos que também fazem parte do jogo da ciência, apesar de irem muito além de seu domínio de produção.

\section{Nota Metodológica}

A tarefa de mapear e analisar a agenda de investigação da Sociologia da Educação no Brasil em período recente implicou uma série de decisões metodológicas e de recortes no que tange ao escopo que o presente estudo foi paulatinamente ganhando. O reconhecimento das clivagens que marcam a SE nesse país, expressas pelo espaço da Sociologia e pelo espaço da Educação, foi crucial para traçar o design adotado.

A partir de uma abordagem mista, quantitativa e qualitativa, 5 etapas foram desenvolvidas, nomeadamente: 1) revisão de literatura especializada; 2) levantamento de informações secundárias; 3) produção de dados a partir dessas informações; 4) organização e tratamento dos dados; e 5) análise dos dados. 
A primeira etapa consistiu basicamente em levantar, ler e estabelecer um diálogo com a literatura especializada, ou seja, com aqueles trabalhos que têm se ocupado de pensar os caminhos da pesquisa em Sociologia da Educação no Brasil. Este momento foi responsável por situar cada vez melhor o objeto de estudo, bem como por proporcionar uma compreensão alargada do cenário atual, e ainda nos possibilitou entender o debate acerca da agenda de pesquisa da área como um elemento significativo de colaboração para o debate.

No segundo momento foram buscadas informações sobre os programas de pósgraduação das duas áreas que este estudo contempla para objetivar a SE no Brasil: a Sociologia e a Educação. As páginas eletrônicas da Coordenação de Aperfeiçoamento de Pessoal de Nível Superior (CAPES) e de cada programa de pós-graduação foram utilizadas, respectivamente, a) no exercício de mapear os programas de pós-graduação das duas áreas que contemplassem linhas de pesquisa diretamente ligadas à Sociologia da Educação; e b) para ter acesso aos pesquisadores que compõem tais linhas de pesquisa. Nesse sentido, temos o seguinte cenário:

Quadro 1. Linhas de pesquisa em Sociologia da Educação nos Programas de Pós-Graduação (PPGs) em Sociologia e em Educação

\begin{tabular}{|c|c|}
\hline \multicolumn{2}{|c|}{ PPGs de Sociologia } \\
\hline Instituições & Linhas de Pesquisa em Sociologia da Educação \\
\hline Universidade Federal do Piauí (UFPI) & $\begin{array}{c}\text { Estado e Sociedade: Trabalho, Educação, Atores } \\
\text { políticos e desigualdades sociais. }\end{array}$ \\
\hline Universidade de Brasília (UnB) & $\begin{array}{c}\text { Eduç̧ãa, Ciência e Tecnologia. } \\
\text { Sociologia da Educação. }\end{array}$ \\
\hline Universidade de São Paulo (USP) & Práticas Educacionais na Sociedade Contemporânea. \\
\hline Universidade Federal de Goiás (UFG) & Educação, Trabalho, Ciência e Tecnologia. \\
\hline Universidade Federal de Pernambuco (UFPE) & $\begin{array}{c}\text { Sociedade e Conhecimento. } \\
\text { (UFRGS) }\end{array}$ \\
\hline Universidade Federal Do Rio Grande do Sul & PPGs de Educação \\
\hline Instituições & Linhas de Pesquisa em Sociologia da Educação \\
\hline Universidade de São Paulo (USP) & Sociologia da Educação. \\
\hline Universidade Estadual de Campinas (UNICAMP) & Educação e Ciências Sociais. \\
\hline Universidade Federal de São Carlos (UFSCAR) & História, Filosofia e Sociologia da Educação. \\
\hline Universidade Federal de Minas Gerais (UFMG) & Sociologia da Educação: escolarização e \\
desigualdades sociais.
\end{tabular}

Fonte: Elaboração própria.

Reconhece-se aqui que tanto há programas em Sociologia com linhas de pesquisa mais genéricas, que também abarcam o debate educacional, ou no caso de programas de Educação, alguns com linhas também mais amplas que incorporam a discussão sociológica. Todavia, nosso recorte almejou visibilizar a institucionalização de uma agenda de pesquisa específica no campo da SE nos dois domínios em questão. 
A produção de dados a partir do levantamento que fora realizado na etapa anterior passou a ocupar-se dos pesquisadores que dão sentido e gerem essas linhas de pesquisa em seus respectivos programas de pós-graduação. Para tal, recorreu-se aos currículos desses sujeitos com vistas a compilar, organizar e tratar os dados relativos aos projetos de pesquisa que estão atualmente em desenvolvimento. Nosso recorte nos levou a 13 professores/pesquisadores nos PPGs de Sociologia e a mais 62 professores/pesquisadores nos PPGs de Educação.

Fugiria do foco e do escopo do artigo aqui apresentado, mas é interessante perceber que entre os pesquisadores vinculados aos programas de Sociologia, majoritariamente encontramos pesquisadores com formação doutoral em Sociologia/Ciências Sociais, ao passo que em Educação encontramos um número maior de pesquisadores com formação doutoral não apenas nessas áreas como também em educação. Recorrentemente encontramos pesquisadores que realizaram um trânsito formativo entre a Educação e as Ciências Sociais, seja realizando a formação inicial em pedagogia e a pós-graduação em ciências sociais como também o inverso. No caso dos pesquisadores vinculados aos programas de Educação também encontramos alguns casos de agentes que realizaram toda a formação acadêmica na área de Educação, o que pode apontar para o fato de que a SE nestes espaços, em algum grau, se constitui como um campo autorreferido, distanciado do debate desenvolvido na Sociologia stricto sensu.

Desse total de professores, foram avaliados inicialmente os projetos que cada um deles desenvolveu. Para a amostra, no entanto, foram selecionados apenas os projetos com o status "em andamento" no momento da coleta dos dados: não foram selecionados projetos que não dialogavam com fenômenos, debates ou teorias educacionais; e, por fim, ativemo-nos apenas a projetos coordenados por professores pertencentes aos programas acadêmicos de pósgraduação da Educação e da Sociologia. O tratamento dos dados ligados a esses projetos de pesquisa e a posterior análise empreendida ganharam sentido, no decorrer do estudo, e aqui neste artigo, à medida que lançam luz ao nosso objeto de investigação. As categorias analíticas que foram construídas ganham centralidade no próximo tópico deste texto.

\section{Resultados e Análises: a Sociologia da Educação}

O levantamento apresentado nesta seção é fruto de uma coleta realizada entre os meses de janeiro e agosto de 2019. Este marcador temporal oferece um ponto de situação sobre a produção de pesquisas desenvolvidas nos programas de pós-graduação de Sociologia e de Educação que se enquadram na grande área Sociologia da Educação.

Ao todo foram encontrados 99 projetos de pesquisa. 8 deles são desenvolvidos nas pósgraduações em Sociologia e 91 são desenvolvidos por professores vinculados à pósgraduações em Educação. À primeira vista, esse número poderia levar a crer que a diferença numérica entre PPGs nestas duas áreas, 21 PPGs em Sociologia e 136 PPGs em Educação , explicaria a diferença do quantitativo de projetos desenvolvidos nas duas áreas. No entanto, 
ao observar os PPGs que possuem linhas de pesquisa relacionadas à Sociologia da Educação temos 6 PPGs em Sociologia e 6 em Educação, ainda que se deva considerar que os programas em educação tendam a ser maiores, contando em alguns casos (como na USP e na UNICAMP) com mais de cem professores credenciados.

O contraste está no número de professores que se dedicam à Sociologia da Educação nestes programas. Os PPGs de Sociologia têm apenas 12 professores que desenvolvem pesquisas sobre temas relacionados à SE, já nos PPGs de Educação são 67 professores. Alguns estudos têm apontado para a carência de trabalhos que tomam a educação como objeto nos PPGs de Sociologia. Gouveia (1989) já apontava para a proeminência de trabalho relacionados à Sociologia da Educação nos PPGs de Educação. Na década de 1990, Neves (1991) destacou que entre 13 PPGs na área de Sociologia, apenas 4 PPGs tinham interesses relacionados à SE.

Destacam-se ainda as diferentes formas de recrutamento de professores nesses dois espaços institucionais, sendo mais recorrentes concursos específicos para SE nas Faculdades de Educação. Não à toa, podemos perceber uma renovação de quadros mais intensa nos Programas de Educação, ao passo que nos de Sociologia, apesar de haver um número menor de docentes, encontramos uma maior concentração de pesquisadores consolidados, que possuem bolsas de produtividade em pesquisa, atuam como professores visitantes no exterior, integram diretorias de sociedades científicas, assessoria para agências de fomento, etc.

Buscando uma rota alternativa à leitura dominante nos balanços sobre a produção acadêmica no campo da SE que afirma haver fragilidades teóricas e metodológicas nas pesquisas desenvolvidas nos PPGs de Educação, propomos questionar se seria o caso de ter se constituído uma tradição nos PPGs em Educação de temas relacionados à SE. E mais, questionar até que ponto as críticas sobre as fragilidades teórico-metodológicas dos trabalhos desenvolvidos nos PPGs de Educação são mecanismos de luta científica por legitimidade no campo acadêmico relacionado à SE no Brasil.

Após este preâmbulo que objetivou apresentar e explicar as linhas gerais do que encontramos no levantamento realizado, problematizando algumas linhas argumentativas de balanços anteriores, buscaremos detalhar os projetos de pesquisa desenvolvidos pela área de SE no Brasil.

Após a coleta dos resumos dos projetos de pesquisa processou-se a primeira categorização dos trabalhos encontrados. Nesta etapa, foram criadas 37 categorias analíticas que variavam de acordo com os títulos e resumos dos projetos. Após isto, processamos nova síntese buscando aproximar projetos que estavam inicialmente em categorias diferentes. Foram os casos, por exemplo, das categorias "ensino de sociologia", "ensino de história" e "ensino de filosofia" que se transformaram em uma categoria, "ensino". Ou ainda o caso das categorias "Gênero e diversidade", "Educação indígena" e "diversidade étnico-racial" que se transformaram na categoria "Educação, gênero e diversidade étnico-racial". Ao final deste trabalho de síntese construímos 21 categorias distribuídas da seguinte maneira: 
Tabela 1. Categorização dos projetos de pesquisa no âmbito da SE

\begin{tabular}{|c|c|c|}
\hline Categorias & $\mathrm{N}^{\mathrm{o}}$ de projetos & $\%$ \\
\hline Ensino superior & 15 & $13 \%$ \\
\hline $\begin{array}{c}\text { Formação de } \\
\text { professores }\end{array}$ & 11 & $9 \%$ \\
\hline Estudo teórico & 10 & $8,5 \%$ \\
\hline $\begin{array}{c}\text { Educação escolar e } \\
\text { justiça social }\end{array}$ & 9 & $8 \%$ \\
\hline $\begin{array}{c}\text { Educação, gênero e } \\
\text { diversidade étnico- } \\
\text { racial }\end{array}$ & 9 & $8 \%$ \\
\hline Trabalho docente & 9 & $8 \%$ \\
\hline Ensino & 8 & $7 \%$ \\
\hline $\begin{array}{c}\text { Estudos sobre a } \\
\text { produção acadêmica }\end{array}$ & 8 & $7 \%$ \\
\hline $\begin{array}{c}\text { Política e legislação } \\
\text { educacional }\end{array}$ & 7 & $6 \%$ \\
\hline Família-escola & 6 & $5 \%$ \\
\hline $\begin{array}{c}\text { Educação e } \\
\text { participação política }\end{array}$ & 4 & $3 \%$ \\
\hline Educação infantil & 4 & $3 \%$ \\
\hline $\begin{array}{l}\text { Intelectuais e } \\
\text { pensamento } \\
\text { pedagógico }\end{array}$ & 4 & $3 \%$ \\
\hline $\begin{array}{c}\text { Educação, patrimônio } \\
\text { e memória }\end{array}$ & 3 & $2,5 \%$ \\
\hline $\begin{array}{l}\text { Educação } \\
\text { profissional }\end{array}$ & 2 & $2 \%$ \\
\hline $\begin{array}{c}\text { Avaliação da } \\
\text { educação básica }\end{array}$ & 1 & $1 \%$ \\
\hline $\begin{array}{c}\text { Educação, ciência e } \\
\text { inovação }\end{array}$ & 1 & $1 \%$ \\
\hline História da Educação & 1 & $1 \%$ \\
\hline $\begin{array}{c}\text { Trajetórias e carreiras } \\
\text { profissionais }\end{array}$ & 1 & $1 \%$ \\
\hline $\begin{array}{c}\text { Outros (Escola e } \\
\text { cinema [1]; Escola e } \\
\text { infraestrutura [1]; } \\
\text { Ação pedagógica [1]; } \\
\text { Cotidiano escolar [1]) }\end{array}$ & 4 & $3 \%$ \\
\hline Total & 117 & $100 \%$ \\
\hline
\end{tabular}

Fonte: Elaboração própria.

À primeira vista chama atenção o número total destoar em relação ao total de projetos apresentado no início desta seção do texto. Isso ocorre porque alguns projetos se encontram em regiões de fronteira entre as categorias. É o caso, por exemplo, do projeto "Ensino de sociologia: formação de professores, conteúdos e recursos de ensino" que foi incluído nas categorias "Formação de professores" e "Ensino". Ou do projeto "Formadores de professores 
presenciais e a distância: entre processos de profissionalização e desprofissionalização" que foi incluído nas categorias "Formação de professores" e "Trabalho docente".

A categoria que somou a maioria dos projetos é "Ensino superior". Em sua composição temos 4 projetos desenvolvidos em PPGs de Sociologia e 11 em PPGs de Educação. Os projetos abordam uma ampla gama de tópicos nesse nível de ensino, desde modelos de ensino superior até internacionalização, incluindo tópicos como desistência, expansão, inclusão e democratização. Curiosamente, dos 8 projetos desenvolvidos nos PPGs de Sociologia, metade deles trata de questões relacionadas ao ensino superior. Esse número reflete a tendência indicada em estudos anteriores (MARTINS; WEBER, 2010; OLIVEIRA; SILVA, 2016). Nesse sentido, a produção atual na área de SE nos PPGs da Sociologia segue a mesma direção indicada por outros levantamentos.

O fato curioso, no entanto, reside no caso dos PPGs da educação. Tradicionalmente, há uma tendência na divisão do trabalho acadêmico quanto os objetos de pesquisa entre estas áreas. Os PPGs de Sociologia se restringem ao estudo do ensino superior, ao passo que os PPGs de Educação se dedicam ao estudo de fenômenos relacionados à educação básica. Os dados indicam haver uma mudança nesta tendência uma vez que os pesquisadores localizados no campo da educação têm desenvolvido projetos relacionados ao ensino superior.

Outro dado curioso é a categoria "Estudo teórico". Foram incluídos nesta categoria apenas trabalhos que relacionavam construções teóricas de diversos autores com fenômenos educacionais. São os casos dos projetos "Teoria crítica, racionalidades e educação", ou do projeto "Educação, Biopolítica e Direitos Humanos". Projetos como, por exemplo, "Hannah Arendt e Walter Benjamin: Eros da amizade e afinidades eletivas" ou "Tensões da teoria sociológica e de suas formas: o conceito de 'constelação' e os processos formativos de teorias da sociedade em circulação", por não relacionar construções teóricas a fenômenos educacionais, não foram incluídos na amostra válida para este trabalho. Mais curioso ainda é a ausência de trabalhos desta categoria em PPGs de Sociologia, o que demonstra um direcionamento mais empirista das pesquisas preocupadas com a educação nesses programas.

A categoria "Ensino", que soma 8 projetos, tem como principal característica a presença marcante de projetos relacionados ao ensino de sociologia. Do total, 6 trabalhos se direcionam para o ensino de sociologia, os outros dois são direcionados ao ensino de história (1) e ao ensino de filosofia (1). Este dado tem relação direta com a retomada da preocupação, no seio da Sociologia, com a questão da disciplina no ensino médio no Brasil - a tensão presença/ausência da sociologia na educação básica, bem como as interrogações acerca do currículo, das práticas pedagógicas, dos livros didáticos e também do Programa Institucional de Bolsas de Iniciação à Docência (PIBID) transformaram-se em questões que não somente reacenderam o interesse dos sociólogos pela educação, mas também passaram inclusive a constituir pontos de concursos na área da SE nos institutos/faculdades de sociologia e ciências sociais das universidades brasileiras. 
Uma categoria apresenta forte concentração institucional, ou seja, muitos projetos são desenvolvidos numa mesma instituição, é a categoria "Família-escola". Dos 6 projetos encontrados 5 se situam no PPG de Educação da Universidade Federal de Minas Gerais. No extremo oposto, a categoria "Ensino superior", além de não apresentar forte concentração institucional, encontrando-se projetos de pesquisa em todo o país, exceto na região norte ${ }^{5}$, apresenta-se distribuída entre os dois campos de conhecimento. Neste levantamento, esta categoria segue a tendência de levantamentos anteriores que apontam esta temática como central das preocupações acadêmicas brasileiras (NEVES, 2002; WEBER, 1992; ROMANELLI; NOGUEIRA; ZAGO, 2013).

Diante desses dados, é possível inferir que algumas categorias se consolidaram como temas clássicos no pensamento sobre SE no Brasil. Na década de 1990, Weber (1992) destacava que as temáticas predominantes eram: Estado e educação; Universidade e sociedade; o professor e sua prática pedagógica; e educação popular. Já no início da década de 2000, Neves (2002) apontava para os seguintes temas prioritários: escolaridade e desigualdades sociais; escola e violência; escola e professor: trabalho e profissão; políticas educacionais; ensino superior em transformação; educação e trabalho; movimentos sociais e educação; e, finalmente, educação e gênero.

Em nosso levantamento, vemos temas tradicionais se mesclarem a temas mais recentes. De um lado temos três blocos de temas que já vinham figurando desde os primeiros levantamentos sobre SE no país (mesmo que com outras nomenclaturas), são eles, a) "formação de professores" e "trabalho docente", que juntos representam 17\% do total de projetos aqui mapeados; b) "educação escolar e justiça social" (8\%), que estabelece uma ponte com aquilo que Neves (2002) apontava como a preocupação com a relação entre educação e desigualdade social; e c) "política e legislação educacional" (6\%), que aparecia em outros levantamentos com trabalhos que estavam preocupados em tratar da atuação do Estado na educação nacional, da educação como política pública social ou ainda da análise de políticas educacionais específicas - neste caso faz-se mister destacar que todas essas frentes de pesquisa continuam a figurar na SE. E, de outro, temos temas mais recentemente incorporados à agenda de pesquisa da SE brasileira e que têm paulatinamente se consolidado, tais como: "educação, gênero e diversidade étnico-racial" (8\%), "estudos sobre a produção acadêmica" (7\%), além da "educação infantil" (3\%) - esta última tem encontrado diálogo direto com a consolidação da chamada Sociologia da Infância em muitos países.

Em síntese, tomando os levantamentos supracitados em olhar comparativo, observamos os seguintes temas eleitos pela comunidade cientifica como prioritários:

\footnotetext{
${ }^{5}$ Não foi encontrado nenhum PPG que apresente em suas linhas de pesquisa temas relacionados à SE na região Norte.

\begin{tabular}{l|l|l|l|l|l} 
(C) Rev. Inter. Educ. Sup. & Campinas, SP & v.6 & $1-21$ & $\mathrm{e} 020044$ & 2020 \\
\hline
\end{tabular}
}


Quadro 2. Temas privilegiados na SE brasileira/Comparação entre balanços (1992/2002/Atual)

\begin{tabular}{|c|c|c|c|}
\hline \multicolumn{4}{|c|}{ Temas privilegiados na SE brasileira } \\
\hline Temáticas & $\begin{array}{c}\text { Levantamento } \\
\text { realizado por Weber } \\
\text { (1992) }\end{array}$ & $\begin{array}{c}\text { Levantamento } \\
\text { realizado por Neves } \\
(\mathbf{2 0 0 2 )})\end{array}$ & Levantamento atual \\
\hline $\begin{array}{l}\text { Reflexões acerca do } \\
\text { ensino superior }\end{array}$ & Universidade e sociedade & $\begin{array}{l}\text { Ensino superior em } \\
\text { transformação }\end{array}$ & Ensino Superior \\
\hline $\begin{array}{l}\text { Reflexões acerca do } \\
\text { trabalho do professor }\end{array}$ & $\begin{array}{c}\text { O professor e sua prática } \\
\text { pedagógica }\end{array}$ & $\begin{array}{l}\text { Escola e professor: } \\
\text { trabalho e profissão }\end{array}$ & $\begin{array}{l}\text { Trabalho e formação } \\
\text { docente }\end{array}$ \\
\hline $\begin{array}{l}\text { Reflexões acerca das } \\
\text { relações entre política e } \\
\text { educação }\end{array}$ & Estado e educação & Políticas educacionais & $\begin{array}{c}\text { Política e legislação } \\
\text { educacional }\end{array}$ \\
\hline $\begin{array}{l}\text { Reflexões acerca das } \\
\text { relações entre educação e } \\
\text { movimentos sociais }\end{array}$ & Educação popular & $\begin{array}{c}\text { Educação e gênero } \\
\text { Movimentos sociais e } \\
\text { educação }\end{array}$ & $\begin{array}{c}\text { Educação, gênero e } \\
\text { diversidade étnico-racial }\end{array}$ \\
\hline
\end{tabular}

Fonte: Elaboração própria.

Passados 27 anos desde o primeiro levantamento considerado neste trabalho, é possível perceber a persistência de temas relacionados ao ensino superior, às políticas educacionais e à profissão docente, o que possivelmente fora reforçado pela aceleração da expansão do ensino superior no Brasil nos últimos anos, e o consequente ingresso de novos públicos na universidade, que tem lançado novos desafios à agenda de pesquisa da SE no Brasil. Pode-se inferir ainda que, no que tange à profissão docente, esse debate ganha centralidade pelas próprias atividades de docência desenvolvidas nas Faculdades de Educação, e pela recente aproximação entre os Departamentos de Ciências Sociais/Sociologia com a reintrodução da sociologia na educação básica a partir de 2008 . No caso de temas relacionados às relações entre educação e movimentos sociais é possível perceber um leve deslocamento na direção de atualizar o repertorio científico para compreender novas demandas impostas pelas mudanças nos movimentos sociais. Nesse sentido, é interessante perceber como temáticas de gênero e de raça foram incorporadas às preocupações científicas, o que tende a se relacionar com o advento das ações afirmativas no sistema educacional.

Por fim, ratifica-se que estas mudanças e deslocamentos na agenda de pesquisa da Sociologia da Educação no Brasil expressam, de forma concomitante, transformações sociais mais amplas na sociedade que acabam por fazer emergir velhas e novas preocupações que adentram o campo científico e as próprias lutas travadas no interior deste campo para a definição e legitimação de uma agenda de pesquisa e seus temas, objetos e referenciais teóricos e metodológicos. Esta compreensão nos permite romper com uma ideia automatista da relação entre problemas sociais e problemas sociológicos, como se o concreto, por meio de uma espécie de hiperempirismo determinasse aquilo de que os pesquisadores se ocupam em cada época, bem como com uma ideia puramente formalista e racionalista da construção de uma agenda de investigação (BOURDIEU; CHAMBOREDON; PASSERON, 2007). 


\section{Conclusões}

A Sociologia da Educação no Brasil é atravessada pela história da própria institucionalização da Sociologia no início do século XX, sendo este o primeiro subcampo desta disciplina a se autonomizar (MEUCCI, 2011), e depois pelas transformações sofridas pelo ensino superior brasileiro na segunda metade deste mesmo século. A Reforma Universitária de 1968, os programas de pós-graduação e a criação das Faculdades de Educação representaram ingredientes fundamentais para a divisão que perdura até os nossos dias entre as áreas da Sociologia/Ciências Sociais e da Educação.

Com base nos trânsitos que os sociólogos realizam entre essas duas áreas - seja na formação, sobretudo no âmbito da pós-graduação, seja na atuação profissional (OLIVEIRA; SILVA, 2016) -, os estudos, pesquisas e a literatura que tem se debruçado sobre a SE no país têm se preocupado em compreender esses dois espaços heterogêneos que formam o que chamamos de campo da SE brasileira.

Tendo isto em vista, este artigo partiu da correlação entre as áreas da Sociologia e da Educação e buscou mapear a agenda de pesquisa que vem se legitimando no cenário recente. Os programas de pós-graduação de Sociologia e de Educação constituíram o lócus inicial de buscas para a construção da base de dados com a qual trabalhamos - e, mais especificamente, os projetos de pesquisa dos sociólogos da educação credenciados nos programas em questão que se encontram em desenvolvimento atualmente foram tomados à análise, com vistas a apreender e analisar a que temas/questões esses pesquisadores têm se dedicado.

Os dados revelam tendências temáticas que cruzam os PPGs da Sociologia e os da Educação. Entre eles, destacamos a continuidade de alguns tópicos, como pesquisas relacionadas ao ensino superior, pesquisas sobre a profissão docente e pesquisas sobre as políticas educacionais. Por outro lado, é possível perceber algumas transformações nos tópicos já indicados por pesquisas anteriores. É o caso de investigações que tratam da relação entre educação e movimentos sociais. Nesse caso, o surgimento de problemas relacionados às discussões de gênero e raça mostra a direção que as transformações científicas tomaram.

Também é importante destacar alguns elementos curiosos do campo de pesquisa da SE no Brasil, nomeadamente: a preferência dos pesquisadores situados nos PPGs de Sociologia por tópicos relacionados ao ensino superior; a concentração institucional de um tópico específico - como os trabalhos que tratam da relação família-escola na Universidade Federal de Minas Gerais; e o movimento de nacionalização das pesquisas sobre o ensino superior, posto que é possível encontrar pesquisadores distribuídos em praticamente todas as regiões do país, excetuando a região Norte.

As continuidades e rupturas que surgem da análise da agenda de pesquisa da SE no Brasil nos falam sobre as transformações em dois níveis diferentes: o nível de disciplina em si, sempre entendido em correlação no campo científico; e o nível de transformações sociais que a sociedade brasileira experimenta em geral. No caso do primeiro nível, atuam aqui as 
forças que têm valor no universo acadêmico, tais como: os pesos das instituições de ensino superior e de pesquisa; as posições que certos grupos de pesquisadores ocupam e como, em virtude de tais posições, eles podem legitimar e pulverizar tendências dentro da agenda de pesquisa; e também a tradição histórica e acadêmica que certas temáticas alcançaram dentro da disciplina, a ponto de se tornar um elemento distintivo tanto para os aspirantes quanto para os pesquisadores mais experientes que a desenvolvem. No segundo nível, a questão é um pouco mais complexa, pois aqui enfrentamos mudanças sociais e suas representações para aqueles que compõem o campo científico: o valor social e o valor científico das questões e problemas que surgem diariamente de maneira imperativa para a sociedade brasileira, juntos, eles corroboram [ou não] sua abordagem analítica e sua incorporação à agenda de pesquisa. Vale a pena assinalar neste ponto que não é raro observarmos pesquisadores ligados à SE - e aqui esta questão se aplica a muitas outras áreas do conhecimento - que ocupam esporadicamente posições no campo político (como secretários/as, consultores/as, entre outras posições), o que também pode constituir um elemento significativo para pensarmos essa possibilidade de fluidez das questões públicas nacionais para o campo científico.

Finalmente, as tendências identificadas neste trabalho recolocam questões clássicas em vários subcampos disciplinares que envolvem os conhecimentos relacionados à SE. É sabido que a SE compõe o currículo de cursos de graduação e pós-graduação, seja de forma mais central com disciplinas específicas, seja de forma mais tangencial com disciplinas cujos conteúdos mesclam debates da Sociologia da Educação com outras questões, tal como a política educacional. Nesse sentido, cabe o questionamento sobre as possíveis relações entre as continuidade e/ou rupturas apontadas no texto e a formação de novas gerações de sociólogos da educação, seja de professores para a Educação Básica ou para o Ensino Superior, pesquisadores ou profissionais que atuam em outros setores - esta reflexão pode apontar para uma nova frente de estudo ligada às relações entre este espaço acadêmico específico e seu papel para além das questões propriamente científicas do campo, desdobrando-se em uma atenção ao papel da SE na formação e renovação dos quadros docentes no país. 


\section{Referências}

ALMEIDA, Ana Maria; HEY, Ana Paula. Sociologia da Educação: olhares sobre um campo em ascensão. In: MICELI, Sergio; MARTINS, Carlos Benedito (Org). Sociologia Brasileira Hoje. São Paulo: Ateliê Editorial, 2018. p. 253-310.

ALTHUSSER, Louis. Ideologia e aparelho ideológico do Estado. Lisboa: Ed. Presença, 1970.

BALL, Stephen J. The Sociology of Education: a disputational account. In: BALL, Stephen J. (org.). The Routledge Falmer Reader in Sociology of Education. Londres: Routledge, 2004. p. 1-12.

BARBOSA, Maria Ligia de Oliveira; GANDIN, Luís Armando. Sociologia da educação brasileira: diversidade e qualidade. BIB, São Paulo, n. 91, p. 1-25, fev. 2020.

BIANCHETTI, Lucídio. O processo de Bolonha e a globalização da educação superior: antecedentes, implementação e repercussões no que fazer dos trabalhadores da educação. Campinas, SP: Mercado de Letras, 2015.

BOURDIEU, Pierre. Para uma sociologia da ciência. Lisboa: Edições 70, 2008.

BOURDIEU, Pierre. Razões Práticas: sobre a teoria da ação. Campinas: Papirus Editora, 2011.

BOURDIEU, Pierre. Método científico e a hierarquia social dos objetos. In: NOGUEIRA, Maria Alice; CATANI, Afrânio Mendes (Orgs.). Escritos de Educação. 4. ed. Petrópolis, RJ: Vozes, 2013. p. 35-42.

BOURDIEU, Pierre; CHAMBOREDON, Jean-Claude; PASSERON, Jean-Claude. O ofício de sociólogo: metodologia da pesquisa na sociologia. Tradução: Guilherme João de Freitas Teixeira. 6. ed. Petrópolis, RJ: Vozes, 2007.

BOURDIEU, Pierre; PASSERON, Jean-Claude. A reprodução. Rio de Janeiro: Ed. Francisco Alves, 1975.

CÊA, Georgia Sobreira dos Santos; SILVA, Camila Ferreira. Mosaicos das sociologias da educação no Brasil: mapeamento da produção do GT-14 da ANPED na primeira década do século XXI. Quaestio, Sorocaba, v. 17, n. 1, p. 215-241, maio 2015.

COSTA, Marcio; NOGUEIRA, Maria Alice. Desiguais oportunidades de escolarização: antigo tema sob novos olhares na Sociedade Brasileira de Sociologia. Revista Contemporânea de Educação, Rio de Janeiro, v. 4, n. 8, p. 228- 233, 2009.

COSTA, Marcio; SILVA, Graziella Moraes. Amor e desprezo: o velho caso entre sociologia e educação no âmbito do GT-14. Revista Brasileira de Educação, Rio de Janeiro, n. 22, p. 101-120, jan./abr. 2003. 
CUNHA, Luiz Antônio. A educação na sociologia: um objeto rejeitado? Cadernos Cedes, n. 27, p. 9-22, 1992.

CURY, Carlos Roberto Jamil. Ideologia e educação brasileira: católicos e liberais. São Paulo: Cortez, 1988.

ESTABLET, Roger. A escola. Revista Tempo Brasileiro, n. 35, p. 93-125, out./nov. 1973.

FORQUIN, Jean Claude (Org). Sociologia da Educação: Dez anos de Pesquisa. Petrópolis: Vozes, 1995.

FOUCAULT, Michel. A arqueologia do saber. Tradução: Luiz Felipe Baeta Neves. 7th ed. Rio de Janeiro: Forense Universitária, 2008.

GOHN, Maria da Glória. Participação e democracia no Brasil: da década de 1960 aos impactos pós-junho de 2013. Petrópolis: Editora Vozes, 2019.

GIDDENS, Anthony. As consequências da modernidade. São Paulo: Editora UNESP, 1997.

GOUVEIA, Aparecida Joly. As Ciências Sociais e a pesquisa sobre educação. Tempo Social, São Paulo, v. 1, n.1, p. 71-79, 1989.

GOUVEIA, Aparecida Joly. Orientações teórico-metodológicas da sociologia da educação no Brasil. Cadernos de Pesquisa, São Paulo, n. 55, p. 63-67, nov. 1985.

MARTINS, Carlos Benedito. Notas sobre a formação de um sistema transnacional de ensino superior. Caderno CRH, Salvador, v. 28, n. 74, p. 291-308, 2015.

MARTINS, Carlos Benedito; WEBER, Silke. Sociologia da Educação: democratização e cidadania. In: MARTINS, Carlos Benedito; MARTINS, Heloisa (Org). Sociologia. São Paulo: ANPOCS, 2010. p. 131-201.

MEUCCI, Simone. Institucionalização da sociologia no Brasil: primeiros manuais e cursos. São Paulo: Hucitec, Fapesp, 2011.

MICELI, Sergio. (1989). Condicionantes do desenvolvimento das ciências sociais. In: MICELI, Sergio (Org.). História das Ciências Sociais no Brasil. São Paulo: Editora Vértice/IDESP/FINEP. p. 72-110.

NEVES, Clarissa Eckert Baeta. Estudos Sociológicos sobre Educação no Brasil. In: MICELI, Sergio (Org.). O que ler na ciência social brasileira 1970-2002. São Paulo; Brasília: Editora Sumaré; CAPES, 2002. p. 351-437.

OLIVEIRA, Amurabi; SILVA, Camila Ferreira da. A Diversidade de Agentes e Agendas na Sociologia da Educação no Brasil. No prelo.

OLIVEIRA, Amurabi; SILVA, Camila Ferreira da. A sociologia, os sociólogos e a educação no Brasil. Revista Brasileira de Ciências Sociais, São Paulo, v. 31, n. 91, p. 1-15, jun. 2016. 
OLIVEIRA, Amurabi; SILVA, Camila Ferreira da. Mapeando a sociologia da educação no Brasil: análise de um campo em construção. Atos de Pesquisa em Educação, Blumenau, v. 9, n. 2, p. 289-315, maio/ago. 2014.

OLIVEIRA, Amurabi; SILVA, Camila Ferreira. The Sociology of Education in Brazil Today. RASE - Revista de Sociología de la Educación, v. 13, n. 1, p. 39-54, 2020.

OLIVEN, Arabela Campos. O GT Educação e Sociedade: um balanço de sua atuação. Anuário de Educação, Rio de Janeiro, v. 97/98, p 319-329, 1998.

ROMANELLI, Geraldo; NOGUEIRA, Maria Alice; ZAGO, Nadir (Org). Família e escola: novas perspectivas de análise. Petrópolis: Editora Vozes, 2013.

SEBASTIÃO, João; CAPUCHA, Luís; MARTINS, Suzana; CAPUCHA, Ana Rita. Sociologia da Educação e construção de políticas educativas: da teoria à prática. RASE Revista de Sociología de la Educación, v. 13, n. 1, p. 7-19, 2020.

SILVA, C. F. (2017). (Ciências da) Educação no Brasil e em Portugal: autonomização dos espaços acadêmicos específicos. 2017. 333f. Tese (Doutorado em Ciências da Educação) Faculdade de Ciências e Tecnologia, Universidade Nova de Lisboa, Lisboa, Portugal, 2017.

SILVA, Camila Ferreira da; ALVES, Mariana Gaio. As aspirações dos aprendizes: doutorandos em educação no Brasil. Cadernos de Pesquisa, São Paulo, v. 48, n. 167, p. 280308, jan./mar. 2018.

SILVA, Graziella Moraes. Sociologia da sociologia da educação: caminhos e desafios de uma policy science no Brasil (1920-79). Braganca Paulista: Universidade São Francisco, 2002.

WEBER, Silke. A produção recente na área de Educação. Cadernos de Pesquisa, São Paulo, n. 81, p. 22-32, maio 1992.

WEBER, Silke. O Professorado e o Papel da Educação na Sociedade. Campinas: Papirus, 1996. 